Article

\title{
Rapid Assessments of Amazon Forest Structure and Biomass Using Small Unmanned Aerial Systems
}

\author{
Max Messinger 1,2,*, Gregory P. Asner ${ }^{3}$ and Miles Silman 1,2 \\ 1 Department of Biology, Wake Forest University, 1834 Wake Forest Rd, Winston Hall, Winston-Salem, \\ NC 27109, USA; silmanmr@wfu.edu \\ 2 Center for Energy, Environment, and Sustainability, Wake Forest University, 1834 Wake Forest Rd., \\ Winston-Salem, NC 27109, USA \\ 3 Department of Global Ecology, Carnegie Institution for Science, 260 Panama St, Stanford, CA 94305, USA; \\ gpa@carnegiescience.edu \\ * Correspondence: messmc9@wfu.edu; Tel.: +1-336-758-3967
}

Academic Editors: Sangram Ganguly, Compton Tucker, Lars T. Waser and Prasad S. Thenkabail Received: 14 May 2016; Accepted: 21 July 2016; Published: 25 July 2016

\begin{abstract}
Unmanned aerial vehicles (UAVs) can provide new ways to measure forests and supplement expensive or labor-intensive inventory methods. Forest carbon, a key uncertainty in the global carbon cycle and also important for carbon conservation programs, is typically monitored using manned aircraft or extensive forest plot networks to estimate aboveground carbon density (ACD). Manned aircraft are only cost-effective when applied to large areas ( $>100,000 \mathrm{ha})$, while plot networks are most effective for total $C$ stock estimation across large areas, not for quantifying spatially-explicit variation. We sought to develop an effective method for frequent and accurate ACD estimation at intermediate scales (100-100,000 ha) that would be sensitive to small-scale disturbance. Using small UAVs, we collected imagery of 516 ha of lowland forest in the Peruvian Amazon. We then used a structure-from-motion (SFM) approach to create a 3D model of forest canopy. Comparing SFM- and airborne Light Detection and Ranging (LiDAR)-derived estimates of canopy height and ACD, we found that SFM estimates of top-of-canopy height (TCH) and ACD were highly correlated with previous LiDAR estimates $(r=0.86-0.93$ and $r=0.73-0.94$ for TCH and ACD, respectively, at $0.1-4$ ha grain sizes), with $r=0.92$ for ACD determination at the 1 ha scale, despite SFM and LiDAR measurements being separated by two years in a dynamic forest. SFM and LiDAR estimates of mean $\mathrm{TCH}$ and mean ACD were highly similar, differing by only $0.4 \%$ and $0.04 \%$, respectively, within mature forest. The technique allows inexpensive, near-real-time monitoring of ACD for ecological studies, payment for ecosystem services (PES) ventures, such as reducing emissions from deforestation and forest degradation (REDD+), forestry enterprises, and governance.
\end{abstract}

Keywords: unmanned aircraft; structure-from-motion; SFM-LiDAR fusion; forest carbon monitoring; light detection and ranging (LiDAR); SUAS

\section{Introduction}

Deforestation currently accounts for $6 \%-17 \%$ of global carbon emissions [1], as well as having negative effects on biodiversity and ecosystem services [2-5]. Carbon conservation is an effort to reduce carbon emissions from deforestation and forest degradation, and to actively manage forests to increase carbon stocks and maintain ecosystem services and biodiversity. A major challenge to this effort, however, has revolved around uncertainty in estimating the spatial heterogeneity of forest carbon stocks and monitoring the responses of those stocks to natural disturbance and land-cover/land-use change (LCLUC) [6,7]. Reducing this uncertainty is critical to estimating future carbon emissions from 
LCLUC and natural processes, as well as management for economic returns in reducing emissions from deforestation and forest degradation (REDD+) and sustainable forestry enterprises.

Conventional methods of estimating aboveground carbon density (ACD) typically include labor-intensive field inventories and/or costly aerial Light Detection and Ranging (LiDAR) overflights [8]. Conventional inventory methods are highly effective in estimating total carbon across large areas but do not provide the ability to accurately map ACD heterogeneity. Further, they may fail to detect disturbance occurring outside of plots, especially if plot selection is biased away from areas experiencing LCLUC $[9,10]$. Conventional aerial active remote sensing alleviates the limitations of field inventories by providing wall-to-wall data coverage, but the cost per hectare is high when used at small or intermediate scales (tens to tens of thousands of ha), making frequent monitoring cost prohibitive [11,12].

Deforestation and other forms of LCLUC, as well as natural forest disturbances, can cause rapid changes in ACD [7], especially in areas threatened by extractive activities such as gold mining and logging, i.e., References [13-15]. When LCLUC occurs at high rates, LiDAR-based monitoring on a three- to five-year time scale is not sufficient to observe patterns in the proliferation of deforestation activity, fine scale changes in forest carbon, and afforestation patterns following disturbance $[15,16]$.

High deforestation rates are common across much of the humid tropics, making locations that would benefit from more frequent carbon monitoring abundant $[13,14,17]$. One such location is the high-biodiversity forest of the Western Amazon basin. Here large investments in transportation infrastructure, sustained high gold prices, and high poverty levels, have caused a rapid expansion of illegal artisanal scale gold mining (ASGM) and illegal logging [15,18]. ASGM is now the largest driver of deforestation in the Madre de Dios region of Southeastern Peru, accounting for over 43,000 ha of forest loss since $2000[15,19]$.

Accurate ACD estimation requires new methodologies to provide frequent, cost-effective ACD estimation at intermediate spatial scales. Recent advances in both small-unmanned aerial vehicles (UAVs) design and UAVs image processing methods have made high-frequency, high spatial resolution monitoring possible $[20,21]$. Open source flight control systems have improved significantly over the past few years, providing for low-cost $(<\$ 300)$ and reliable autonomous aircraft control.

Application of computer-vision techniques now makes precise three-dimensional (3D) modeling of forest structure possible. Structure-from-motion (SFM), a computer vision technique that is an expansion of traditional photogrammetric techniques, uses overlapping images to reconstruct a scene in 3D [22]. SFM, unlike conventional stereo-image pairs, uses a large number of images from many viewpoints in reconstruction, making it a powerful tool for high-resolution 3D imaging of large areas, with reconstructions from aerial imagery accurate to sub-meter levels in $x, y$, and $z$ [23-27]. Any type of passive imaging sensor can be used, ranging from small, inexpensive point-and-shoot cameras to high-end multispectral sensors. Because the optical parameters of the sensor are calculated during the reconstruction process [22], the methodology can even use images collected from different sensors. The flexibility of SFM means that UAVs are capable of collecting imagery for the monitoring of forest structural characteristics and forest carbon over large areas (thousands of ha), limited only by the performance of the UAVs and computational resources available for data processing.

The goal of this study was to deploy UAVs, collect imagery of tropical lowland forest, and develop imagery analysis techniques to produce estimates of forest carbon at an accuracy comparable to that of aerial LiDAR while maintaining a sufficiently low cost of operation to allow for frequent data collection. Specifically, we asked (1) how well can UAV-based reconstructions match LiDAR based reconstructions of forest structure (canopy height) and ACD? and (2) what is the dependence of reconstruction accuracy on grain size of the analysis, and how does it compare to LiDAR-based studies of tropical forest? 


\section{Materials and Methods}

\subsection{Study Site}

The aircraft operational procedures and data collection techniques were developed during numerous test flights in the vicinity of Wake Forest University in North Carolina, USA. ACD estimation was conducted with data from a 516 ha area of lowland rainforest surrounding the Los Amigos

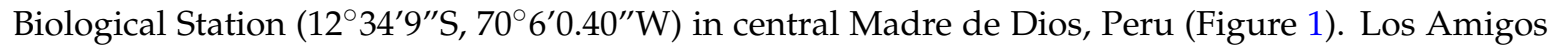
was selected as it includes primary upland terra firma, floodplain, and swamp forest types along with primary succession, secondary succession, and gold mining activity.

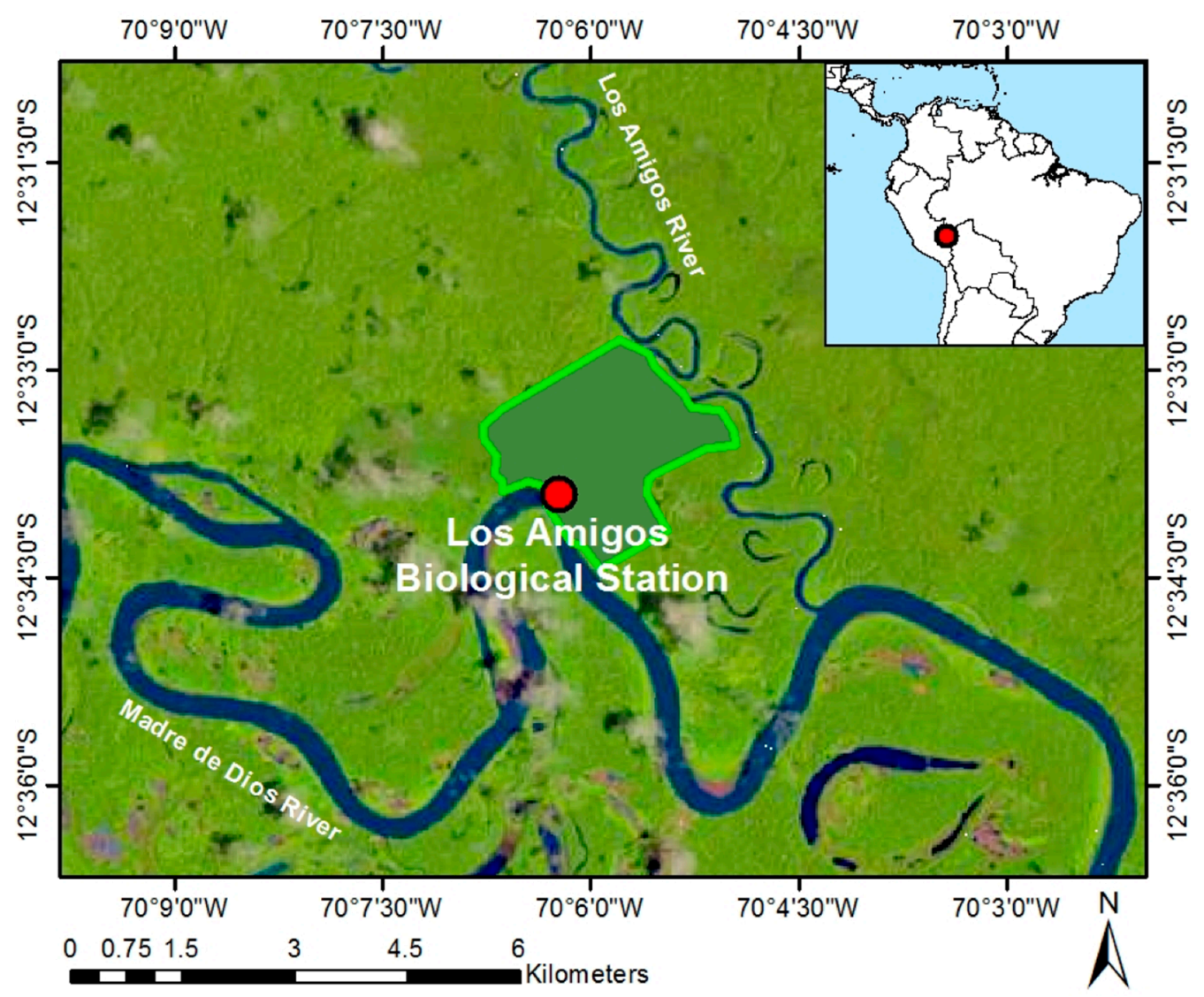

Figure 1. The Los Amigos Biological Station, identified in red, and surrounding area. Green areas are the forest areas imaged.

The site has field inventory for portions of the imaged areas and LiDAR coverage of the full area from overflights by the Carnegie Airborne Observatory (CAO) in 2009 and 2013 using the AToMS sensor system [28]. CAO AToMS is an advanced remote sensing system operated by the Carnegie Institution for Science that integrates imaging spectrometer and LiDAR systems for the study of forest structure, functional biochemistry, carbon content, and diversity.

\subsection{Aircraft Operation and Data Collection}

UAV data presented here were collected using a small, fixed-wing remote sensing aircraft (developed in the Wake Forest University UAVs laboratory, commercialized as the Kestrel, Linn Aerospace LLC, Winston-Salem, NC, USA) (Figure 2) and a Canon S110 RGB camera (Canon Inc., Tokyo, Japan). UAV data were collected during March of 2015. The aircraft was operated using autonomous flight along a predefined grid pattern over the target area using the 3DRobotics Pixhawk flight control system (3DRobotics Inc., Berkeley, CA, USA). Image collection was conducted at altitudes 
between 200 and $250 \mathrm{~m}$ above ground level (170-220 m above canopy) and at a nominal airspeed of $16-20 \mathrm{~m} / \mathrm{s}$. At this altitude, the ground sample distance (GSD) of the imagery was $6.2-7.7 \mathrm{~cm}$. The camera was triggered by the autopilot to provide adequate overlap to allow for the image processing procedure described below. The distance between images varied with altitude, but in all cases provided a $75 \%-85 \%$ overlap between consecutive images and $50 \%$ between images in adjacent transects in the flight plan.

LiDAR data was collected over the study site in 2013 using the CAO AToMS sensor system [28]. A digital terrain model (DTM) of the area was created using the LiDAR data according to the methods outlined in Asner and Mascaro [29]. Data collection flights were conducted at $2000 \mathrm{~m}$ above ground level, providing a density of one point per $1.25 \mathrm{~m}^{2}$. All areas were collected with $50 \%$ overlap with adjacent flight transects, ultimately yielding two points per $1.25 \mathrm{~m}^{2}$. A canopy height model (CHM) was also created according to the methods in Asner and Mascaro [29], for comparison to and validation of the CHM created using the UAVs imagery.

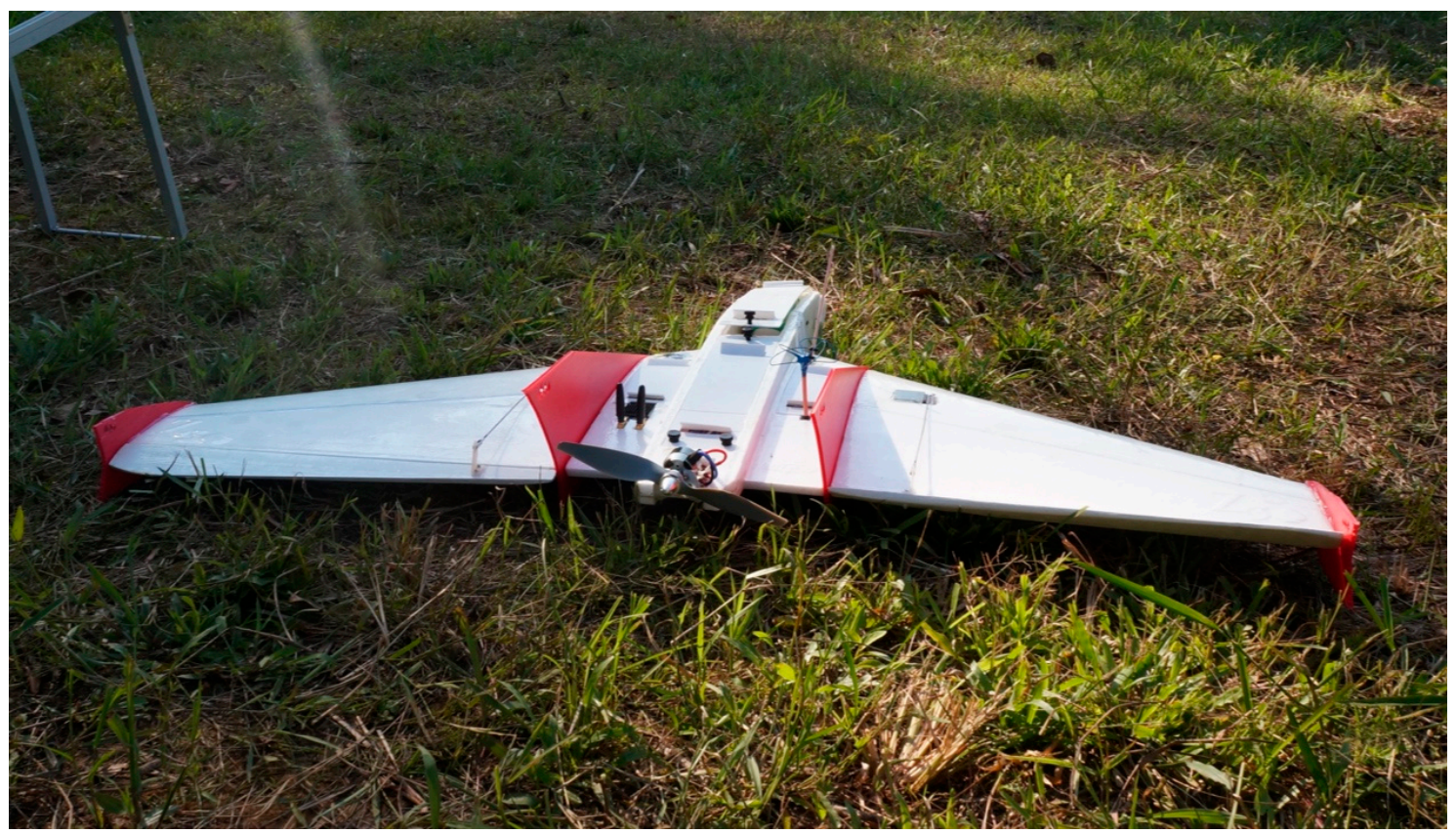

Figure 2. The small, medium-endurance, electric, fixed-wing aircraft used to collect the data presented here.

\subsection{Image Georeferencing and Structure-from-Motion Processing}

Images were georeferenced following the flights using the aircraft's flight log. The timestamp values of the images were matched to time points in the flight log and their corresponding global positioning system (GPS) position data. The accuracy of this georeferencing is limited by the accuracy of the consumer-grade GPS receiver on the aircraft $( \pm 2.5 \mathrm{~m})$. Ground control points (GCPs) were not used, as placing them in remote areas is labor intensive and makes their use infeasible in regional-scale monitoring missions. After georeferencing, images were processed in Agisoft Photoscan Professional (Agisoft LLC, St. Petersburg, Russia; see Reference [30] for overview of methodology; see Table A1 for parameters used). Photoscan is a photogrammetry tool that uses a set of computer vision algorithms known as structure-from-motion (SFM) to: (1) provide highly accurate registration of individual images; (2) develop scene-wide three-dimensional point-cloud models using overlapping images; and (3) produce georeferenced orthoimages and digital canopy models (DCMs). The three-dimensional scene is reconstructed by (1) identifying unique features in a set of images; (2) identifying images with common features; (3) solving camera positions by minimizing distance between common features; 
and (4) using multi-view stereopsis to accurately reconstruct the three-dimensional scene [22]. GSD of the DCM in this study was $1 \mathrm{~m}$; Photoscan resampled the raw point cloud from the native resolution (6.2-7.7 $\mathrm{cm}$ point spacing) to the regular $1 \mathrm{~m}$ raster grid using bilinear interpolation. Internal testing has indicated that the $X Y$ georeferencing error in the orthoimagery and DCMs is $<5 \mathrm{~m}$ and the relative elevation error is $<1 \mathrm{~m}$. We found object height measurements made using SFM data to be as or more accurate than conventional field measurements using a hypsometer.

\subsection{SFM to LiDAR Model Registration}

The 5-m XY georeferencing accuracy of the DCM produced through SFM does not allow precise registration with the LiDAR product and is insufficient for calculation of canopy height, especially in areas of sharp terrain relief. In order to overcome this limitation, the SFM-derived DCM was manually registered to the LiDAR-derived digital terrain model (DTM) and CHM using ENVI 5.0 (Exelis Inc., McLean, VA, USA). Terrain and forest features, which were identifiable in both products were selected as GCPs and the SFM-derived DCM was then warped to the LiDAR-derived data using a $1^{\circ}$ polynomial model. During this process the SFM DCM was also resampled from $1 \mathrm{~m}$ GSD to $5 \mathrm{~m}$ using a cubic convolution in order to match the GSD of the LiDAR CHM.

After correcting for XY positional error, we then corrected for scene-wide $Z$ error. When the aircraft is powered on, a pre-flight calibration takes place that sets the GPS-derived altitude above sea level as the baseline for the flight. During flight, the aircraft uses the on-board barometer to determine the relative altitude above that baseline. This method results in a precise but inaccurate altitude estimate due to the poor Z-accuracy of the consumer-grade GPS [30]. In order to correct for this scene-wide $Z$ offset, we determined the elevation of a number of ground and water points throughout the scene in the SFM and LiDAR data and used them as Z control points. We then calculated the difference in elevation between the control points to determine the Z-error in the SFM data and adjusted the elevation values of the SFM DCM.

\subsection{Canopy Height Model Creation and Evaluation}

In order to calculate ACD, we first calculated the difference between the LiDAR-derived DTM and the SFM-derived DCM, resulting in a $5 \mathrm{~m}$ resolution LiDAR-SFM fusion CHM (Figure 3). We then analyzed the effect of CHM pixel size, or grain size, on canopy height accuracy. Others have found a saturating relationship between grain size and the correlation between RS-derived ACD data and field measurements [31,32]. Averaging fine-scale spatial heterogeneity into larger blocks causes a sharp increase in model performance at small grain sizes that saturates quickly. We downsampled the $5 \mathrm{~m}$ ( 0.0025 ha grain size) resolution CHM to 10, 30, 70, 100, 140, and $200 \mathrm{~m}$ sizes (roughly corresponding to $0.01,0.1,0.5,1,2$, and 4 ha grain size) using pixel aggregation resampling in order to determine the best grain size for ACD estimation. These various height models were then plotted against the LiDAR-derived CHM and their relationship was assessed using the coefficient of determination $\left(\mathrm{R}^{2}\right)$ and the root mean square error (RMSE) of the relationship for each grain size. 


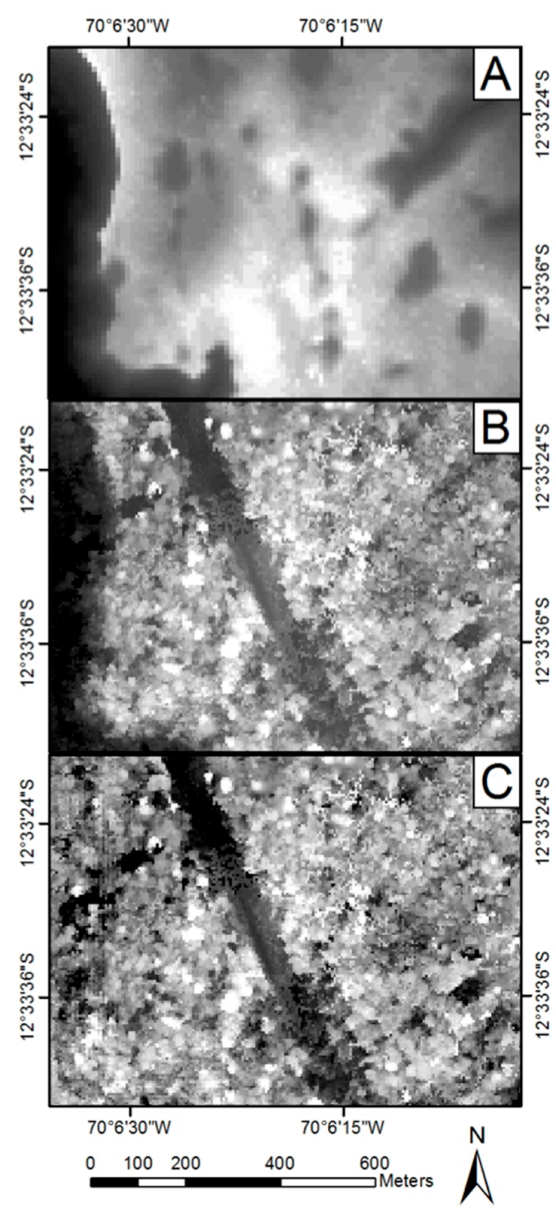

Figure 3. The process of calculating canopy height using SFM and LiDAR data. (A) The LiDAR terrain model is subtracted from (B) the SFM canopy model; $(\mathbf{C})$ resulting in a CHM with terrain removed.

\subsection{Aboveground Carbon Estimation}

We used the CHM to calculate ACD using the methods developed by Asner and Mascaro [29] for use with LiDAR-derived canopy height data. The method is advantageous as it incorporates regional-level measurements of wood density and basal area, providing a significant improvement over models which only use canopy height [33-35]. The model provides a plot-level estimate of carbon density, as opposed to estimation of individual tree biomass [30], providing a much more rapid and automated method of ACD estimation and making it easier to apply at large spatial scales. The following plot-level allometric equation (Equation (1)) was used:

$$
E A C D=a T C H^{b 1} B A^{b 2} \rho_{B A} b 3
$$

where EACD is estimated aboveground carbon density, top-of-canopy height (TCH) is top of canopy height, BA is the regional average basal area, $\rho_{\mathrm{BA}}$ is the regional average basal area-weighted wood density, and $\alpha, b 1, b 2$, and b3 are coefficients estimated from the data (Table 1).

Table 1. The parameters used in Equation (1), drawn from Asner and Mascaro [29].

\begin{tabular}{ccccccc}
\hline Parameter & $\boldsymbol{B A}\left(\mathbf{m}^{\mathbf{2}} \cdot \mathbf{h a}^{-\mathbf{1}}\right)$ & $\boldsymbol{\rho}_{\boldsymbol{B A}}\left(\mathbf{g} \cdot \mathbf{c m} \mathbf{c m}^{-3}\right)$ & $\boldsymbol{\alpha}$ & $\boldsymbol{b 1}$ & $\boldsymbol{b} \mathbf{2}$ & $\boldsymbol{b 3}$ \\
\hline Value & 23.8 & 0.53 & 3.8358 & 0.2807 & 0.9721 & 1.3763 \\
\hline
\end{tabular}


In our estimate of carbon density, we use the basal area, wood density, and coefficients from Asner and Mascaro [29] for the moist forests of Southern Peru, which were derived using data from the study site.

\subsection{Validation}

We validated our results by comparing SFM-derived canopy height and ACD estimates to their LiDAR-derived counterparts. SFM and LiDAR-derived data were compared pixel-wise to determine the relationship of the canopy height and carbon density measurements from the different methods.

\section{Results}

\subsection{Top of Canopy Height}

We found SFM- and LiDAR-derived TCH to be in close agreement. The degree of correlation between methods was related to grain size, as anticipated (Figure 4). Correlations increased rapidly with grain size up to a distinct sill at the 0.1 ha grain size, beyond which they increased more slowly up to the largest size assessed, 4 ha $\left(R^{2}{ }_{0.01 h a}=0.61, R^{2}{ }_{4 h a}=0.86\right)$. The observed pattern of $R^{2}$ saturation with grain size is very similar to that described in Asner and Mascaro [29]. SFM and LiDAR were well correlated at the 0.5 ha grain size, $\left(r=0.89, R^{2}=0.79\right)$ which was chosen to carry out further analyses.

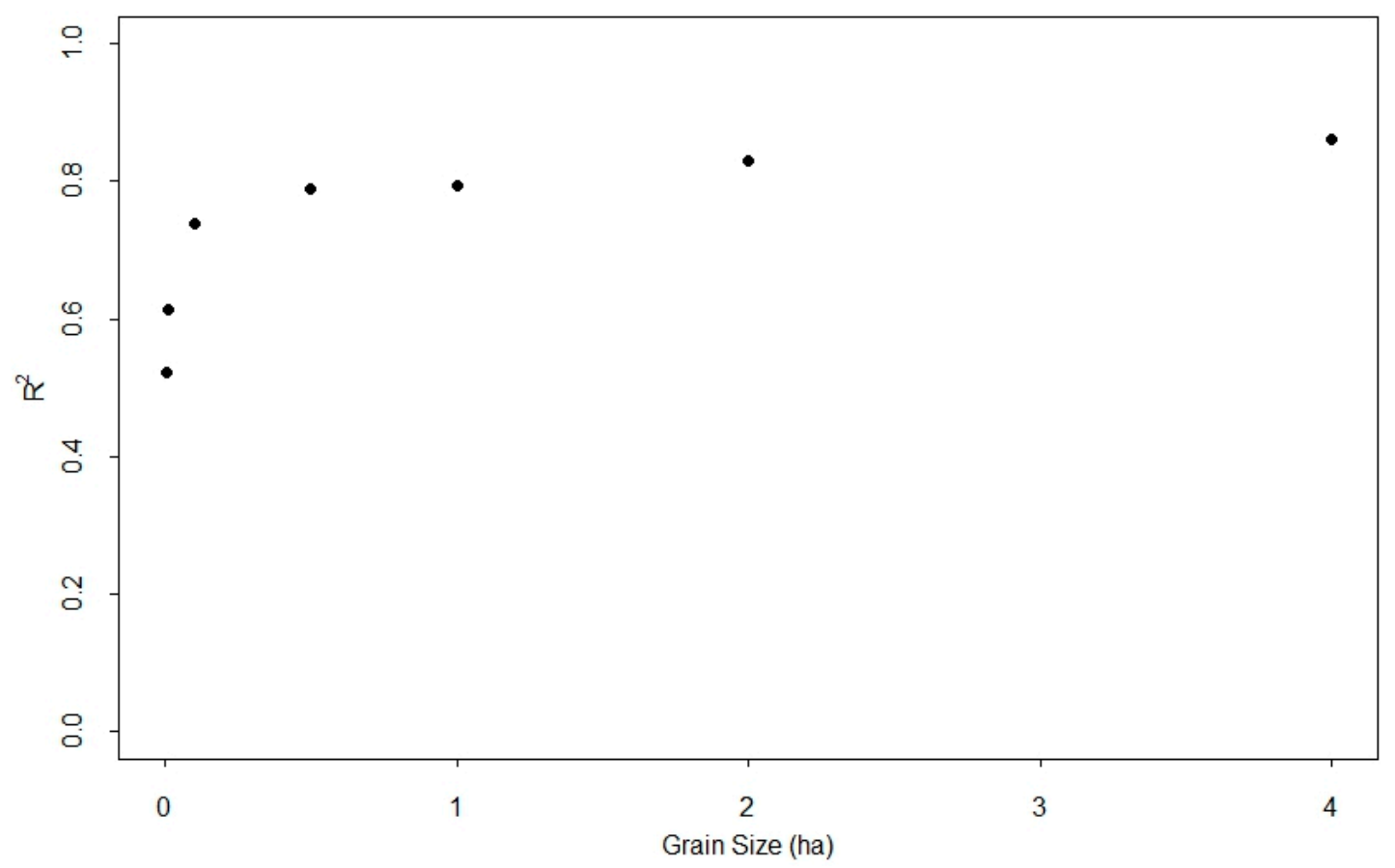

Figure 4. The saturating effect of grain size on top-of-canopy height $(\mathrm{TCH}) \mathrm{R}^{2}$.

SFM- and LiDAR-derived measurements of canopy height at varying grain sizes are shown in Figure 5. Mean canopy height throughout the scene, including areas known to be mature upland forest, floodplain forest, primary succession, and regenerating tree-fall gaps, was $19.46 \pm 7.20 \mathrm{~m}$ in the SFM CHM and $19.50 \pm 6.15 \mathrm{~m}$ in the LiDAR CHM. Mean height in a subset only including mature upland forest was $21.89 \pm 3.38 \mathrm{~m}$ in the SFM CHM and $21.81 \pm 2.93 \mathrm{~m}$ in the LiDAR CHM. 


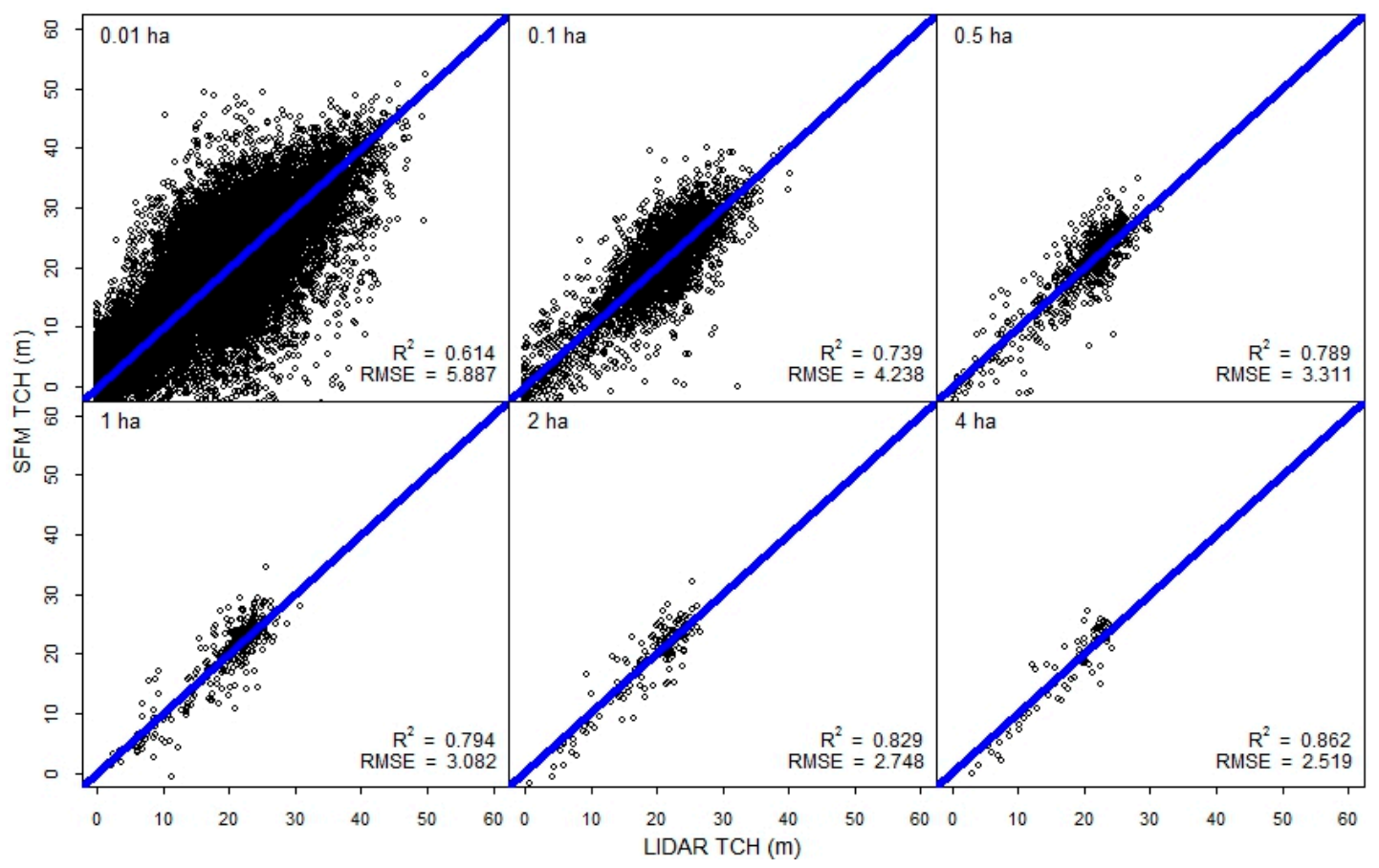

Figure 5. The effect of grain size on top-of-canopy height $(\mathrm{TCH})$ correlation.

\subsection{Aboveground Carbon Density}

As with TCH, SFM and LiDAR derived estimates of ACD were highly correlated (Figure 6). At the 0.5 ha grain size, mean ACD for the area was estimated at $78.64 \pm 10.52 \mathrm{Mg} \cdot \mathrm{C} \cdot \mathrm{ha}^{-1}$ with SFM and $78.86 \pm 9.26 \mathrm{Mg} \cdot \mathrm{C} \cdot \mathrm{ha}^{-1}$ using $\operatorname{LiDAR}\left(\mathrm{R}^{2}=0.80\right)$. The mean ACD for an area of mature primary forest was estimated at $82.72 \pm 3.82 \mathrm{Mg} \cdot \mathrm{C} \cdot \mathrm{ha}^{-1}$ for SFM and $82.69 \pm 3.29 \mathrm{Mg} \cdot \mathrm{C} \cdot \mathrm{ha}^{-1}$ with $\mathrm{LiDAR}\left(\mathrm{R}^{2}=0.78\right)$.

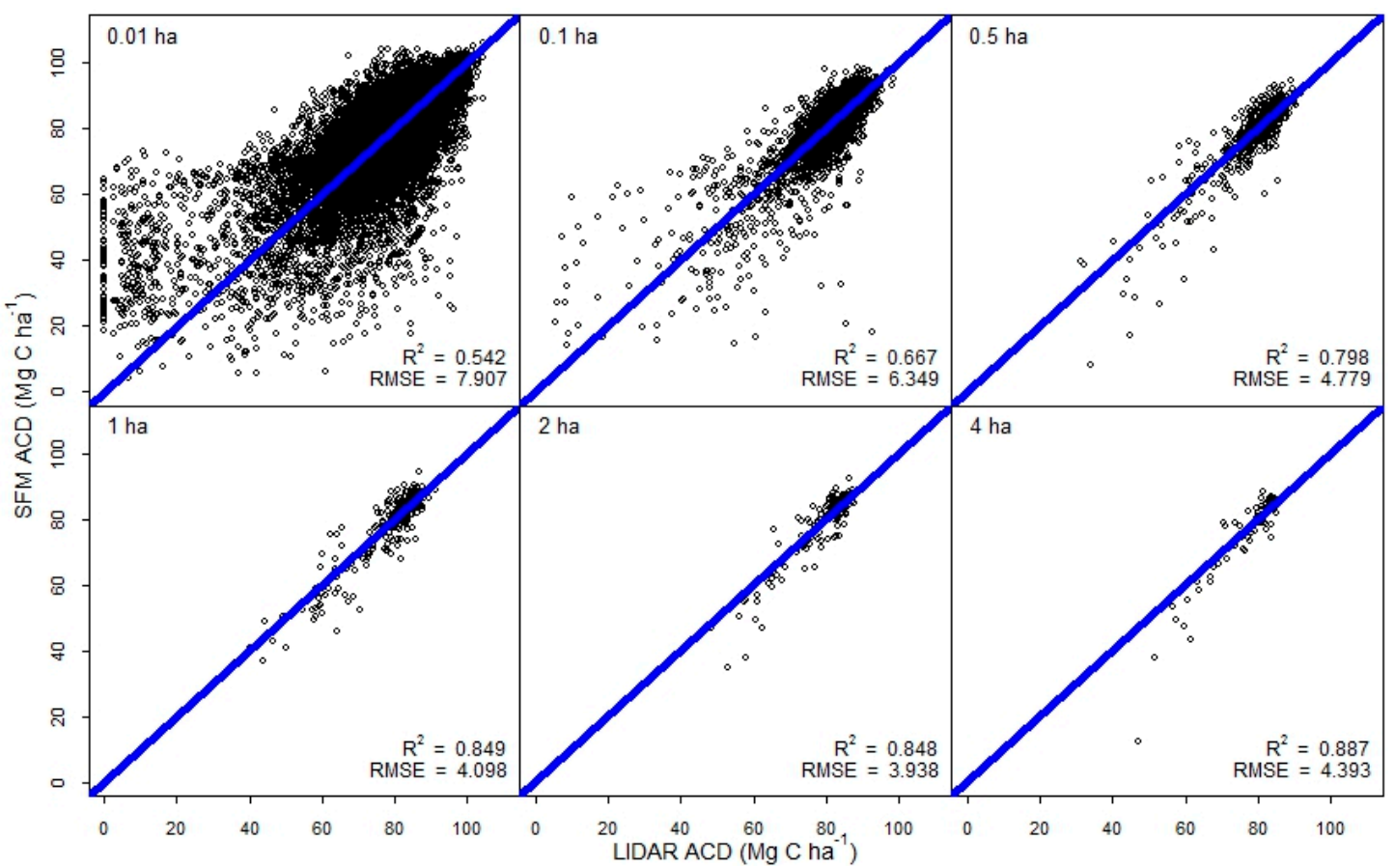

Figure 6. The effect of grain size on aboveground carbon density (ACD) correlation. 
The same trend of increasing correlation as grain size increases that is seen with top-of-canopy height $(\mathrm{TCH})$ is also seen with aboveground carbon density (ACD) (Figure 7). SFM-derived ACD is consistently higher than LiDAR-derived ACD at smaller grain sizes with this effect disappearing at the 0.5 ha scale and above.

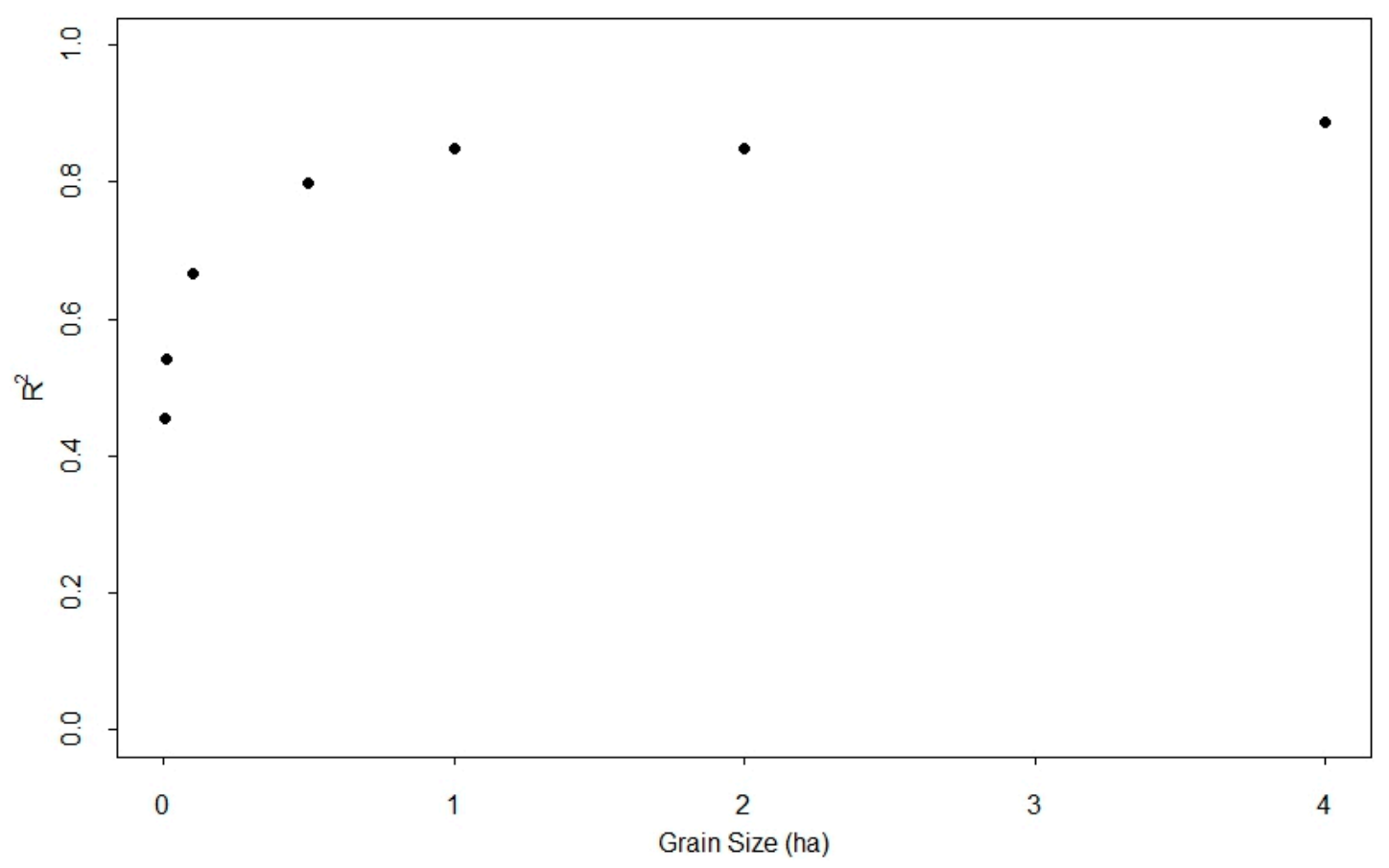

Figure 7. The saturating effect of grain size on ACD $\mathrm{R}^{2}$.

\section{Discussion}

Photo-based SFM and LiDAR estimates of TCH and ACD are highly correlated at the stand level, with SFM reproducing LiDAR canopy height to within $10 \mathrm{~cm}$ and $0.25 \mathrm{Mg} \cdot \mathrm{C} \cdot \mathrm{ha}^{-1}$, respectively, or error rates of roughly $0.5 \%$ and $0.05 \%$. Within mature upland forest, ACD estimates improved to within $0.05 \mathrm{Mg} \cdot \mathrm{C} \cdot \mathrm{ha}^{-1}$. SFM analysis is sensitive to top-of-canopy structure and correlates well with LiDAR modeling of canopy and produces precise estimates of forest ACD with established allometric equations developed for use with LiDAR. Moreover, due to the high similarity between LiDAR and SFM data, the latter can serve as a replacement for LiDAR estimation of AGB and ACD when LiDAR is unavailable due to cost or other constraints, especially where LiDAR or P-band or UHF RADAR-derived DTMs are available.

At small grain sizes, SFM overestimates ACD as compared to LiDAR. While we do not have sufficient information to determine the cause of the small discrepancy between SFM and LiDAR at small grain sizes is a known effect and could arise from inaccuracies in both the LiDAR and SFM data. St. Onge and Achaichia [25] have hypothesized that imagery products such as stereoimagery and SFM actually provide a truer reconstrction than LiDAR due to the relatively low point density of LiDAR [25], which can cause portions of canopies to be missed. The discrepancy may also be the result of processes inherent to the SFM reconstruction, such as point cloud noise filtering, interpolation techniques, as well as the geometric limitations involved in having multiple images that "see" into the same small gap from different angles. This effect does, however, disappear at 0.5 ha and larger grain sizes as the influence of small gaps is averaged out, making 0.5 ha and larger ACD products highly accurate across the range of biomass values. Further, while small gaps are extremely common and have impacts on forest ecology, they have little effect on ACD [36,37].

We expect SFM reconstruction of TCH and ACD to be similar to LiDAR in performance across all forested biomes, with SFM-derived TCH measurements appearing to be highly accurate in a 
number of forest types including temperate broadleaf, managed conifer, and boreal, e.g., [12,24,26,38], making UAVs a powerful forest monitoring tools with broad applicability. The low cost of UAV operation allows for imagery collection on a fine temporal scale, making it valuable in restoration ecology, carbon conservation, land management, and governance.

The SFM-LiDAR data fusion technique presented in this study advances UAV remote sensing capabilities, expanding coverage to large spatial scales in forest biomes, even those inaccessible from the ground. To the best of our knowledge, this is the first use of UAV imagery to estimate forest carbon in the tropics and the first time anywhere ACD has been estimated at spatial scales $>50$ ha without operator-defined ground control points (GCPs). Estimating ACD at the stand level and without GCPs represents a significant improvement in the scalability of the technique, allowing for ACD estimation from UAVs on the scale of thousands or tens of thousands of ha with little change to the methods. While in its infancy, previous studies have used UAV imagery to measure tree height and estimate biomass $[12,24,30,38]$. Several studies to date have used slow-moving rotary-wing UAVs flying at lower altitudes, i.e., Reference [30]. Here, we demonstrate that fixed-wing aircraft flying at roughly twice the altitude and three times the ground speed of rotary-wing aircraft are capable of achieving similar precision of height estimates, but over much larger spatial scales.

UAVs are particularly well-suited to mapping and monitoring forest aboveground carbon stocks in intermediate-size (thousands to tens of thousands of hectares) areas experiencing rapid LCLUC. The fine temporal resolution afforded by UAVs can provide rapid detection of new deforestation and monitoring of regrowth post-disturbance. Along with recent advances in the development of satellite imagery analysis systems capable of detecting fine-scale deforestation, such as CLASlite [39], UAVs can help provide rapid identification of deforested areas, estimate the residual carbon after deforestation, and monitor regrowth through time on temporal and spatial scales that are prohibitively expensive with airborne LiDAR. UAVs may also provide the ability to accurately estimate carbon loss due to forest degradation rather than deforestation, which has been difficult with other passive remote sensing analyses [6].

SFM from UAVs is a passive remote sensing tool that provides capabilities similar to active remote sensing systems, such as LiDAR. It will not only aid in improving our estimates of the effects of deforestation and degradation on the carbon cycle but will also allow for improved governance through rapid detection, assessment, and dissemination of changes in carbon stocks and ecosystem services.

\subsection{Improvements}

The work presented here represents the initial stages of the development of routine forest monitoring using UAVs. There remain a number of inefficiencies and limitations in our data collection and processing framework which are addressed below.

Poor accuracy of CHM georeferencing resulting from the use of consumer-grade GPS is the primary limitation to the method. Locational inaccuracy makes $\mathrm{CHM}$ registration in the XY plane and Z-axis correction necessary before canopy height can be calculated, representing a labor-intensive bottleneck in the image processing workflow. The use of higher-precision differential GPS should eliminate the need for manual registration by reducing error in $\mathrm{X}, \mathrm{Y}$, and $\mathrm{Z}$ to significantly less than $1 \mathrm{~m}[40]$.

A second limitation in this study is our use of relatively low-quality imaging sensors. We believe that a significant portion of the error present in the DCM reconstruction is due to low-quality images. The small point-and-shoot cameras used in this study (and generally in the UAVs community) do not perform well in low light and are known to have a high susceptibility to vibration and high flight speed $[12,30,38]$. We believe that the transition to higher-quality cameras with larger, more sensitive, and higher resolution sensors will not only provide improved GSD but also reduce image blur and poor pixel definition present with point-and-shoot cameras.

Finally, we believe that future comparisons of SFM and LiDAR data would benefit from contemporaneous collection of both datasets. While the correlation between the LiDAR and SFM 
data is quite high despite there being a nearly two-year gap between the collection of each dataset, contemporaneous collection would eliminate a source of error in determining the similarity of SFM to LiDAR products. For example, we identify a slight underestimation of ACD by SFM, as compared to LiDAR, especially at large grain sizes ( 2 and $4 \mathrm{ha}$ ). We are unsure if this is due to real changes in ACD over time or other factors, such as systematic underestimation of ACD by SFM in low-biomass areas or poor performance of the allometric model in such areas.

\subsection{Future Directions}

The primary factor preventing our adoption of cameras with improved sensors and lenses is currently the weight-carrying limitation of our UAVs. Additionally, the aircraft used for this study has a flight time of $45 \mathrm{~min}$, only allowing it to cover roughly 250 ha per flight. The use of larger aircraft powered by gasoline engines will allow for data collection over much larger areas with more advanced imaging sensors. Aircraft under development at the Wake Forest UAV Lab will provide the capability to carry $5 \mathrm{~kg}$ of sensors or other equipment for over four hours, allowing for coverage of approximately 13,000 ha per flight at a GSD of $7.7 \mathrm{~cm}$, with higher resolutions possible. With the deployment of this aircraft will come the ability to monitor LCLUC and estimate ACD on the scale of hundreds of thousands of ha or even national scales, and will certainly be suitable for even the largest REDD+ projects or forestry operations.

The final limitation we identify with our technique is the need for an initial LiDAR collection to provide the terrain model used in canopy height calculation. While LiDAR data has been collected over many deforestation hot spots in the tropics, most areas do not have LiDAR data and much of the data which does exist is not publicly available. The recent release of global 30-m resolution terrain data from the shuttle radar topography mission (SRTM) may, however, eliminate the need for a LiDAR-derived DTM. SRTM is known to have an offset between RADAR-determined surface and true ground surface in densely forested areas [41] and further study should be dedicated to determining if it is a feasible alternative to LiDAR-derived terrain data.

\section{Conclusions}

Van der Werf et al. [1] estimated that 6\%-17\% of global carbon emissions, or $0.6-1.7 \mathrm{Pg} \cdot \mathrm{yr}^{-1}$, were the result of forest loss and degradation. Since that time, considerable effort has been focused on understanding forest carbon cycles, and on ways to alter it in order to generate revenue and sequester carbon. While conventional remote sensing estimates of forest carbon have greatly improved our understanding of carbon density and the emissions from deforestation and degradation, there remain cases where higher spatial or temporal resolution tools are needed.

While a frequently-cited benefit of UAVs is ultra-high spatial resolution data [42,43], here we provide an example of an application where they provide other unique benefits. UAVs provide a remote sensing platform with a low operating cost allowing for frequent data collection, low flight altitude allowing for operation under clouds, and the ability to collect data over areas of a few hundred or few thousand hectares where use of a manned aircraft is not feasible due to deployment costs. Rapid LCLUC, as is occurring in much of the tropics, and highly dynamic natural environments with frequent disturbance and/or rapid regrowth, require such a platform to allow for collection of 3D data with high temporal resolution. Before the advent of unmanned aircraft, 3D data could generally only be collected infrequently due to the high operating cost of LiDAR-equipped manned aircraft. Here, we demonstrate that UAVs are a valuable tool in forest carbon monitoring as they provide high quality 3D data comparable to LiDAR-derived data and allow for high temporal resolution due to low operating costs.

In addition to carbon monitoring, we see UAVs as a transformative tool in applied conservation, especially for management of PES and REDD+ projects and enforcement of environmental law. The market value of ecosystem services and forest carbon is largely driven by the certainty, or lack thereof, in determining the integrity of those services and the quantity of carbon present. Errors in 
estimation lead to a decrease in market value as the conservativeness principle is used to bias toward underestimation $[44,45]$. UAVs are a cost-effective tool for high-quality forest monitoring and their use should result in higher certainty in the value of PES and REDD+ products and, subsequently, higher market prices for them. UAVs will also provide land managers and governments the information necessary for effective real-time protection of property and enforcement of environmental laws at a low cost. Much of South America, including most of Amazonian Peru, is chronically undergoverned. The cost of enforcement across vast rural areas far from central governments plays a large role in this problem. Low-cost UAVs will reduce enforcement costs through inexpensive detection of illegal activity and targeted enforcement efforts. The future of UAVs applications is promising as a revolutionizing technology for the monitoring and protection of forests and other natural resources.

Acknowledgments: We thank those who made this work possible, especially unmanned aircraft expert Marcus Wright, as well as Michael Anderson, Bill Smith, and Paul Pauca for their advice, Tim King for his piloting expertise, and Billy Nicholson for his faithful support in the field and his willingness to pay the penultimate price in the name of science. The Amazon Conservation Association provided hospitality as well as financial and logistical support. Support came from the Wake Forest Center for Energy, Environment, and Sustainability, The Andrew Sabin Family Foundation, and The Winston-Salem Foundation. Carnegie Airborne Observatory data collection, processing and analyses were funded by the John D. and Catherine T. MacArthur Foundation. The Carnegie Airborne Observatory is made possible by the Avatar Alliance Foundation, John D. and Catherine T. MacArthur Foundation, Gordon and Betty Moore Foundation, Mary Anne Nyburg Baker and G. Leonard Baker Jr., and William R. Hearst III.

Author Contributions: Messinger and Silman conceived the study and all authors contributed to its design. Messinger carried out data collection with UAVs and Asner contributed LiDAR-derived data products. Processing and analysis of UAV imagery and comparison to LiDAR data products was carried out by Messinger. Messinger wrote the article with editorial advice and from Silman and Asner. All authors participated in the review process.

Conflicts of Interest: The authors declare no conflict of interest. The founding sponsors had no role in the design of the study; in the collection, analyses, or interpretation of data; in the writing of the manuscript, and in the decision to publish the results.

\section{Abbreviations}

The following abbreviations are used in this manuscript:

$\begin{array}{ll}\text { UAV } & \text { Unmanned aerial vehicle } \\ \text { ACD } & \text { Aboveground carbon density } \\ \text { SFM } & \text { Structure-from-motion } \\ \text { LiDAR } & \text { Light detection and ranging } \\ \text { TCH } & \text { Top of canopy height } \\ \text { PES } & \text { Payment for ecosystem services } \\ \text { REDD+ } & \text { Reducing emissions from deforestation and forest degradation } \\ \text { LCLUC } & \text { Land cover/land-use change } \\ \text { ASGM } & \text { Artisanal-scale gold mining } \\ \text { CAO } & \text { Carnegie Airborne Observatory } \\ \text { AToMS } & \text { Airborne Taxonomic Mapping System } \\ \text { GSD } & \text { Ground sample distance } \\ \text { CHM } & \text { Canopy height model } \\ \text { GPS } & \text { Global positioning system } \\ \text { GCP } & \text { Ground control point } \\ \text { DCM } & \text { Digital canopy model } \\ \text { DTM } & \text { Digital terrain model } \\ \text { RMSE } & \text { Root mean square error } \\ \text { EACD } & \text { Estimated aboveground carbon density } \\ \text { UHF } & \text { Ultra-high frequency } \\ \text { RADAR } & \text { Radio detection and ranging } \\ \text { CLASlite } & \text { Carnegie Landsat Analysis System lite } \\ \text { SRTM } & \text { Shuttle RADAR Topography Mission } \\ & \end{array}$




\section{Appendix A}

Table A1. The parameters used for SFM reconstruction in Agisoft Photoscan Professional. These parameters apply to software version 1.2.1 and available parameters may change in future releases. Accuracy and quality parameters were chosen to provide the most accurate product. Elsewhere, defaults were selected as they provide high reconstruction performance in almost all cases.

\begin{tabular}{cc}
\hline \multicolumn{1}{c}{ Parameter Name } & Selected Value \\
\hline Accuracy & \\
Pair preselection & Highest \\
Key point limit & Reference \\
Tie point limit & 40,000 \\
Build dense cloud & 4000 \\
\hline \multicolumn{2}{c}{ Build DEM } \\
Quality \\
Depth filtering \\
\hline \multicolumn{2}{c}{ Altra high } \\
\hline Source data & Dense cloud \\
Interpolation & Enabled \\
Point classes & All \\
Resolution (m/pix) & 1 \\
\hline
\end{tabular}

\section{References}

1. Van der Werf, G.R.; Morton, D.C.; DeFries, R.S.; Olivier, J.G.J.; Kasibhatla, P.S.; Jackson, R.B.; Collatz, G.J.; Randerson, J.T. $\mathrm{CO}_{2}$ emissions from forest loss. Nat. Geosci. 2009, 2, 737-738. [CrossRef]

2. Koh, L.P.; Wilcove, D.S. Is oil palm agriculture really destroying tropical biodiversity? Conserv. Lett. 2008, 1, 60-64. [CrossRef]

3. Peres, C.A. Synergistic effects of subsistence hunting and habitat fragmentation on Amazonian forest vertebrates. Conserv. Biol. 2001, 15, 1490-1505. [CrossRef]

4. Román-Dañobeytia, F.; Huayllani, M.; Michi, A.; Ibarra, F.; Loayza-Muro, R.; Vázquez, T.; Rodríguez, L.; García, M. Reforestation with four native tree species after abandoned gold mining in the Peruvian Amazon. Ecol. Eng. 2015, 85, 39-46. [CrossRef]

5. Bunker, D.E.; DeClerck, F.; Bradford, J.C.; Colwell, R.K.; Perfecto, I.; Phillips, O.L.; Sankaran, M.; Naeem, S. Species loss and aboveground carbon storage in a tropical forest. Science 2005, 310, 1029-1031. [CrossRef] [PubMed]

6. De Sy, V.; Herold, M.; Achard, F.; Asner, G.P.; Held, A.; Kellndorfer, J.; Verbesselt, J. Synergies of multiple remote sensing data sources for REDD+ monitoring. Curr. Opin. Environ. Sustain. 2012, 4, 696-706. [CrossRef]

7. Baccini, A.; Goetz, S.J.; Walker, W.S.; Laporte, N.T.; Sun, M.; Sulla-Menashe, D.; Hackler, J.; Beck, P.S.A.; Dubayah, R.; Friedl, M.A.; et al. Estimated carbon dioxide emissions from tropical deforestation improved by carbon-density maps. Nat. Clim. Chang. 2012, 2, 182-185. [CrossRef]

8. Lu, D.; Chen, Q.; Wang, G.; Liu, L.; Li, G.; Moran, E. A survey of remote sensing-based aboveground biomass estimation methods in forest ecosystems. Int. J. Digit. Earth 2014, 9, 63-105. [CrossRef]

9. Fisher, J.I.; Hurtt, G.C.; Thomas, R.Q.; Chambers, J.Q. Clustered disturbances lead to bias in large-scale estimates based on forest sample plots. Ecol. Lett. 2008, 11, 554-563. [CrossRef] [PubMed]

10. Marvin, D.C.; Asner, G.P.; Knapp, D.E.; Anderson, C.B.; Martin, R.E.; Sinca, F.; Tupayachi, R. Amazonian landscapes and the bias in field studies of forest structure and biomass. Proc. Natl. Acad. Sci. USA 2014, 111, E5224-E5232. [CrossRef] [PubMed]

11. Erdody, T.L.; Moskal, L.M. Fusion of LiDAR and imagery for estimating forest canopy fuels. Remote Sens. Environ. 2010, 114, 725-737. [CrossRef]

12. Dandois, J.P.; Ellis, E.C. High spatial resolution three-dimensional mapping of vegetation spectral dynamics using computer vision. Remote Sens. Environ. 2013, 136, 259-276. [CrossRef] 
13. Achard, F.; Eva, H.D.; Stibig, H.; Mayaux, P.; Richards, T.; Malingreau, J.; Achard, F.; Eva, H.D.; Stibig, H.; Mayaux, P.; et al. Determination of deforestation rates of the world's humid tropical forests. Science 2002, 297, 999-1002. [CrossRef] [PubMed]

14. Achard, F.; Beuchle, R.; Mayaux, P.; Stibig, H.-J.; Bodart, C.; Brink, A.; Carboni, S.; Desclée, B.; Donnay, F.; Eva, H.D.; et al. Determination of tropical deforestation rates and related carbon losses from 1990 to 2010. Glob. Chang. Biol. 2014, 20, 2540-2554. [CrossRef] [PubMed]

15. Asner, G.P.; Llactayo, W.; Tupayachi, R.; Ráez Luna, E. Elevated rates of gold mining in the Amazon revealed through high-resolution monitoring. Proc. Natl. Acad. Sci. USA 2013, 110, 18454-18459. [CrossRef] [PubMed]

16. Asner, G.P. Automated mapping of tropical deforestation and forest degradation: CLASlite. J. Appl. Remote Sens. 2009, 3, 033543. [CrossRef]

17. Hansen, M.C.; Potapov, P.V.; Moore, R.; Hancher, M.; Turubanova, S.A.; Tyukavina, A.; Thau, D.; Stehman, S.V.; Goetz, S.J.; Loveland, T.R.; et al. High-resolution global maps of 21st-century forest cover change. Science 2013, 342, 850-853. [CrossRef] [PubMed]

18. Swenson, J.J.; Carter, C.E.; Domec, J.-C.; Delgado, C.I. Gold mining in the Peruvian Amazon: Global prices, deforestation, and mercury imports. PLoS ONE 2011, 6, e18875. [CrossRef] [PubMed]

19. Finer, M.; Novoa, S. MAAP Synthesis \#1: Patterns and Drivers of Deforestation in the Peruvian Amazon. Available online: http://maaproject.org/2015/maap-synthesis1/ (accessed on 6 November 2015).

20. Koh, L.P.; Wich, S. Dawn of drone ecology: low-cost autonomous aerial vehicles for conservation. Trop. Conserv. Sci. 2012, 5, 121-132.

21. Anderson, K.; Gaston, K.J. Lightweight unmanned aerial vehicles will revolutionize spatial ecology. Front. Ecol. Environ. 2013, 11, 138-146. [CrossRef]

22. Snavely, N.; Seitz, S.M.; Szeliski, R. Modeling the world from Internet photo collections. Int. J. Comput. Vis. 2008, 80, 189-210. [CrossRef]

23. Dandois, J.P.; Ellis, E.C. Remote sensing of vegetation structure using computer vision. Remote Sens. 2010, 2, 1157-1176. [CrossRef]

24. Lisein, J.; Pierrot-Deseilligny, M.; Bonnet, S.; Lejeune, P. A Photogrammetric workflow for the creation of a forest canopy height model from small unmanned aerial system imagery. Forests 2013, 4, 922-944. [CrossRef]

25. St-Onge, B.; Achaichia, N. Measuring forest canopy height using a combination of LiDAR and aerial photography data. Int. Arch. Photogramm. Remote Sens. Spat. Inf. Sci. 2001, XXXIV-3/W4, 131-137.

26. Puliti, S.; Olerka, H.; Gobakken, T.; Næsset, E. Inventory of small forest areas using an unmanned aerial system. Remote Sens. 2015, 7, 9632-9654. [CrossRef]

27. Wallace, L.; Lucieer, A.; Malenovský, Z.; Turner, D.; Vopěnka, P. Assessment of forest structure using two UAV techniques: A comparison of airborne laser scanning and structure from motion (SfM) point clouds. Forests 2016, 7, 62. [CrossRef]

28. Asner, G.P.; Knapp, D.E.; Boardman, J.; Green, R.O.; Kennedy-Bowdoin, T.; Eastwood, M.; Martin, R.E.; Anderson, C.; Field, C.B. Carnegie Airborne Observatory-2: Increasing science data dimensionality via high-fidelity multi-sensor fusion. Remote Sens. Environ. 2012, 124, 454-465. [CrossRef]

29. Asner, G.P.; Mascaro, J. Mapping tropical forest carbon: Calibrating plot estimates to a simple LiDAR metric. Remote Sens. Environ. 2014, 140, 614-624. [CrossRef]

30. Dandois, J.; Olano, M.; Ellis, E. Optimal altitude, overlap, and weather conditions for computer vision UAV estimates of forest structure. Remote Sens. 2015, 7, 13895-13920. [CrossRef]

31. Asner, G.P.; Powell, G.V.N.; Mascaro, J.; Knapp, D.E.; Clark, J.K.; Jacobson, J.; Kennedy-Bowdoin, T.; Balaji, A.; Paez-Acosta, G.; Victoria, E.; et al. High-resolution forest carbon stocks and emissions in the Amazon. Proc. Natl. Acad. Sci. USA 2010, 107, 16738-16742. [CrossRef] [PubMed]

32. Mascaro, J.; Detto, M. Evaluating uncertainty in mapping forest carbon with airborne LiDAR. Remote Sens. Environ. 2011, 115, 3770-3774. [CrossRef]

33. Chave, J.; Andalo, C.; Brown, S.; Cairns, M. Tree allometry and improved estimation of carbon stocks and balance in tropical forests. Oecologia 2005, 145, 87-99. [CrossRef] [PubMed]

34. Asner, G.P.; Mascaro, J.; Muller-Landau, H.C.; Vieilledent, G.; Vaudry, R.; Rasamoelina, M.; Hall, J.S.; van Breugel, M. A universal airborne LiDAR approach for tropical forest carbon mapping. Oecologia 2012, 168, 1147-1160. [CrossRef] [PubMed] 
35. Mitchard, E.T.A.; Feldpausch, T.R.; Brienen, R.J.W.; Lopez-Gonzalez, G.; Monteagudo, A.; Baker, T.R.; Lewis, S.L.; Lloyd, J.; Quesada, C.A.; Gloor, M.; et al. Markedly divergent estimates of Amazon forest carbon density from ground plots and satellites. Glob. Ecol. Biogeogr. 2014, 23, 935-946. [CrossRef] [PubMed]

36. Boyd, D.; Hill, R.; Hopkinson, C.; Baker, T. Landscape-scale forest disturbance regimes in Southern Peruvian Amazonia. Ecol. Appl. 2013, 23, 1588-1602. [CrossRef] [PubMed]

37. Chambers, J.; Negron-Juarez, R.; Magnabosco Marra, D.; Di Vittorio, A.; Tews, J.; Roberts, D.; Ribeiro, G.; Trumbore, S.; Higuchi, N. The steady-state mosaic of disturbance and succession across an old-growth Central Amazon forest landscape. Proc. Natl. Acad. Sci. USA 2012, 110, 3949-3954. [CrossRef] [PubMed]

38. Gaulton, R.; Taylor, J.; Watkins, N. Unmanned Aerial Vehicles for Pre-Harvest Biomass Estimation in Willow (Salix spp.) Coppice Plantations. Available online: https://geouav.teledetection.fr/papers/GEOSPATIAL_ WEEK_2015_284.pdf (accessed on 4 November 2015).

39. Asner, G. Tropical forest carbon assessment: Integrating satellite and airborne mapping approaches. Environ. Res. Lett. 2009, 4, 034009. [CrossRef]

40. Turner, D.; Lucieer, A.; Wallace, L. Direct georeferencing of ultrahigh-resolution UAV imagery. IEEE Trans. Geosci. Remote Sens. 2014, 52, 2738-2745. [CrossRef]

41. Bourgine, B.; Baghdadi, N. Assessment of C-band SRTM DEM in a dense equatorial forest zone. Extern. Geophys. Clim. Environ. 2005, 337, 1225-1234. [CrossRef]

42. Cunliffe, A.; Brazier, R.; Anderson, K. Ultra-fine grain landscape-scale quantification of dryland vegetation structure with drone-acquired structure-from-motion photogrammetry. Remote Sens. Environ. 2016, 183, 129-143. [CrossRef]

43. Getzin, S.; Wiegand, K.; Schöning, I. Assessing biodiversity in forests using very high-resolution images and unmanned aerial vehicles. Methods Ecol. Evol. 2012, 3, 397-404. [CrossRef]

44. Grassi, G.; Monni, S.; Federici, S. Applying the conservativeness principle to REDD to deal with the uncertainties of the estimates. Environ. Res. Lett. 2008, 3, 035005. [CrossRef]

45. Angelsen, A.; Brown, S.; Loisel, C.; Peskett, L.; Streck, C.; Zarin, D. Reducing Emissions from Deforestation and Forest Degradation (REDD): An Options Assessment Report; International Information System for the Agricultural Science and Technology (AGRIS); Food and Agriculture Organization of the United Nations (FAO): Rome, Italy, 2009.

(C) 2016 by the authors; licensee MDPI, Basel, Switzerland. This article is an open access article distributed under the terms and conditions of the Creative Commons Attribution (CC-BY) license (http://creativecommons.org/licenses/by/4.0/). 